\title{
POPULATION CONSEQUENCES OF A PREDATOR-INDUCED HABITAT SHIFT BY TROUT IN WHOLE-LAKE EXPERIMENTS
}

\author{
Peter A. Biro, ${ }^{1,3}$ John R. Post,${ }^{1}$ And Eric A. Parkinson ${ }^{2}$ \\ ${ }^{1}$ Division of Ecology, Department of Biological Sciences, University of Calgary, 2500 University Drive N.W., Calgary, \\ Alberta, Canada T2N IN4 \\ ${ }^{2}$ Fisheries Research and Development Section, British Columbia Ministry of Fisheries, University of British Columbia, \\ Vancouver, British Columbia, Canada V6T $1 \mathrm{Z4}$
}

\begin{abstract}
In a replicated whole-lake experiment, we (a) tested for the existence of a flexible habitat shift in response to predator presence in age-0 rainbow trout (Oncorhynchus mykiss) at risk of cannibalism and (b) evaluated the population-level consequences of habitat shifts in terms of growth and survival over their first growing season. Daphnid food and adult trout predators were substantially more abundant in pelagic than in littoral habitats. Age- 0 trout used all habitats in populations without adult trout predators, whereas age- 0 trout were observed only in the less profitable littoral habitat in populations with adult trout. Consequently, mean fall mass of age- 0 trout in the presence of predators was almost half that observed in populations without adult trout. Despite the shift in habitat use, age0 trout experienced $90 \%$ mortality when adult trout predators were present, in comparison to only $36 \%$ mortality when absent. We conclude that the commonly observed habitat shifts by fish at risk of predation, observed at smaller scales, do in fact occur at the whole-system scale over long time intervals. These results suggest that fish are able to perceive risk at large spatial scales and thus take advantage of profitable (but normally risky) habitats when predators are absent, or move to less profitable refuge habitats when predators are present.
\end{abstract}

Key words: antipredator behavior; behavior; habitat use; mortality; Oncorhynchus mykiss; pre dation; predation risk; predator-prey system; rainbow trout; salmonid.

\section{INTRODUCTION}

Predators have effects on the abundance and size structure of prey populations that can influence community structure and dynamics (e.g., Sih 1987, Lima and Dill 1990, Lima 1998a, $b$, Sih et al. 1998). Consequently, predation is an extremely strong selective force and is thought to be important in the evolution of behavioral and morphological adaptations that reduce predation (e.g., Lima and Dill 1990). A vast number of studies show that animals can balance costs and benefits while foraging under risk of predation (Lima $1998 b$ ). Many of these studies come from fish predatorprey systems that are amenable to experimental manipulation. Since food abundance and risk of predation are often correlated in aquatic systems, these studies typically show effects of predator presence on fish prey that include increased use of refuge habitats, decreased growth as a consequence of using less profitable refuges, reduced survival, and increased food resources outside the refuge (see review in Diehl and Eklöv 1995). Similar patterns of adaptive antipredator behavior have been found in both vertebrate and invertebrate predator-prey systems (e.g., Sih 1987, Lima and Dill 1990, Lima 1998b, Karels et al. 2000).

Much of the empirical literature that shows flexible and adaptive antipredator behavior comes from labo-

Manuscript received 1 November 2001; revised 12 July 2002; accepted 18 July 2002 . Corresponding Editor: K. O. Winemiller.

${ }^{3}$ E-mail: pbiro@ucalgary.ca ratory or mesocosm experiments of short duration (Lima $1998 a, b$ ). It does not necessarily follow that prey in natural environments similarly assess and respond to variable risk at larger spatial and temporal scales. Recent reviews identify this gap in our knowledge and suggest that adaptive behavioral responses of prey to risk of predation in natural conditions is poorly documented, and that the absence of realistic field experiments are a major impediment to our understanding of how behavior influences population and community dynamics in natural systems (e.g., Walters and Juanes 1993, Lima and Zollner 1996, Sutherland 1996, Fryxell and Lundberg 1997, Lima 1998b, Luttbeg and Schmitz 2000, Schmitz 2001). Small-scale experiments and even mesocosm experiments run the risk of creating conditions where rates of interaction between predators and prey are elevated in confinement. Furthermore, experiments of short duration do not reveal whether variation in behavior has effects on growth or mortality over the long term (Lima 1998b, Schmitz 2001). Acknowledging these possibilities, recent experiments and reviews suggest that laboratory experiments may overestimate the degree of antipredator behavior expected in the field (Abramsky et al. 1996, Irving and Magurran 1997, Wolff and Davis-Born 1997, Lima 1998b, Lima and Bednekoff 1999). Studies conducted at more realistic spatiotemporal scales are needed to test results obtained at smaller scales (e.g., Schindler 1990, Carpenter 1996, see also Persson et al. 1999). In 
TABLE 1. Treatment allocation, morphometric statistics, mean seasonal daphnid abundance (littoral and pelagic habitats), and estimates of the number of age- 0 rainbow trout (Oncorhynchus mykiss) killed by bird predators for each of the experimental lakes in British Columbia, Canada.

\begin{tabular}{|c|c|c|c|c|c|c|c|}
\hline \multirow[b]{2}{*}{ Lake } & \multirow{2}{*}{$\begin{array}{l}\text { Surface } \\
\text { area (ha) }\end{array}$} & \multirow{2}{*}{$\begin{array}{c}\text { Max. } \\
\text { depth (m) }\end{array}$} & \multirow{2}{*}{$\begin{array}{c}\text { Mean } \\
\text { depth }(\mathrm{m})\end{array}$} & \multirow{2}{*}{$\begin{array}{l}\text { Adult trout } \\
\text { predators } \\
\text { (treatment) }\end{array}$} & \multicolumn{2}{|c|}{ Daphnid biomass $(\mu \mathrm{g} / \mathrm{L})$} & \multirow{2}{*}{$\begin{array}{c}\text { No. age-0 } \\
\text { trout killed } \\
\text { by birds }\end{array}$} \\
\hline & & & & & Littoral & Pelagic & \\
\hline BP 1 & 1.9 & 8 & 2.3 & present & 457 & 2540 & 453 \\
\hline BP 2 & 1.4 & 7 & 3.2 & present & 291 & 2369 & 317 \\
\hline BP 3 & 1.4 & 6 & NA & absent & 147 & 2406 & 205 \\
\hline SMOKE & 2.0 & 9 & 2.8 & absent & 180 & 2573 & 723 \\
\hline
\end{tabular}

Note: $\mathrm{NA}=$ not available.

some cases, this may only be achieved by whole-system experiments that allow expression of the full suite of spatial and temporal aspects of predator and prey behavior (e.g., Persson et al. 1996, 1999, Post et al. 1999).

The purpose of this study was to test for evidence of flexible habitat use (facultative habitat use) in young prey fish cohorts, and to evaluate its population-level consequences at the scale of whole aquatic ecosystems. We performed a replicated whole-lake experiment to determine (1) whether, and to what extent, age-0 rainbow trout (Oncorhynchus mykiss) alter their use of habitat in response to the presence of adult rainbow trout predators, and (2) the consequences of differential habitat use in terms of growth and mortality over an entire growing season. Lakes are ideal for such experiments for several reasons. First, each lake is a discrete and independent replicate. Second, mortality and growth consequences of behavioral variation can be rigorously assessed in lakes since they are closed systems, and in our case, fish populations are created entirely by stocking. Third, there is evidence supporting the existence of a spatial trade-off between growth and mortality rates for age- 0 trout in our study lakes and in other lakes (e.g., Tabor and Wurtsbaugh 1991). In our lakes, risk of predation mortality is related to the spatial distribution of adult trout, whereby deeper habitats are more dangerous than shallow habitats (Post et al. 1998, 1999, Landry et al. 1999). Abundance of daphnid plankton, which comprises $>90 \%$ of age- 0 trout diet, also increases with depth (Landry 1997, Landry et al. 1999, Post et al. 1999). Because growth of age-0 trout is closely related to food abundance (Post et al. 1999), the use of inshore habitats by age- 0 trout must represent a trade-off between growth and mortality rates. However, we know of only one whole-lake study that has examined habitat use by young fish in the presence vs. absence of cannibalistic adults, and that study was not replicated, nor did it quantify growth or survival (Landry et al. 1999).

We tested the following predictions: (1) The presence of predators will restrict the distribution of age- 0 trout to the littoral zone, whereas, in the absence of trout predators, age- 0 trout will predominantly use the profitable pelagic habitat; (2) growth of age- 0 trout will be lower when predators are present as a consequence of inhabiting the less profitable littoral zone; and (3) age-
0 trout mortality will be greater in the presence of adult trout.

\section{Methods}

Experimental design

We implemented a single factor experiment using four entire lakes (BP1, BP2, BP3, and SMOKE) and manipulated predator presence (present/absent) while keeping constant intitial prey fish density. The experiment was conducted over an entire growing season that extended from early July to mid-October 2000. Initial prey fish density (age-0 rainbow trout) was set at 15000 trout/ha to allow for comparisons of mortality with earlier experiments and to allow for low-level destructive fish sampling during the growing season. Age0 rainbow trout were raised at the Fraser Valley Trout Hatchery (British Columbia Fisheries Branch) from eggs collected from a wild population in Tunkwa Lake, British Columbia. Fish were stocked within several days of absorbing their yolk at a mean fork length of $27 \mathrm{~mm}$ and mean mass of $0.184 \mathrm{~g}(n=200)$. Stocking took place on 13 July 2000, at a time when wild young emerge from nest substrates in the area. Replicate batch samples of age- 0 trout were weighed, and all individuals were counted to obtain a mass density used to estimate the number to be stocked. To reduce and equalize predator densities of survivors from previous experiments (lakes BP1 and BP2), we began by netting with a constant effort for five net-nights in late April 2000 (see Estimation of mortality and growth). Initial predator density (adult rainbow trout) was estimated to be 1000-1 200 trout/ha in the predator treatment and zero in the predator-free treatment (Table 1). Predator treatments consisted of adult trout ranging in size from 15 to $30 \mathrm{~cm}$ fork length at the time of age- 0 trout stocking. Predator-free treatments were achieved by a complete winterkill of all fish in two lakes due to anoxia; total absence of adults was later confirmed by intensive gillnetting in the fall.

\section{Lake selection}

The four lakes used for our experiment were all located within $5 \mathrm{~km}$ of one another in south-central British Columbia, Canada $\left(49^{\circ} 50^{\prime}-49^{\circ} 56^{\prime} \mathrm{N}, 120^{\circ} 33^{\prime}-\right.$ $\left.120^{\circ} 34^{\prime} \mathrm{W}\right)$. The lakes were small, lack natural repro- 
duction of trout, and contain no other fish species. The lakes were $1.4-2.0$ ha in size and were relatively shallow (maximum depths 7-9 m; Table 1). The lakes had 4 to $6 \mathrm{~m}$ of pelagic habitat above the thermocline, below which is anoxic during summer stratification and thus unavailable to fish. Additional physical and biological descriptors of the lakes can be found in Post et al. (1999).

These lakes were chosen from a larger set of experimental lakes because they have all experienced periodic winterkills in recent years that allowed us to have a treatment free of adult trout predators. In addition, the lakes also have very similar productivity and zooplankton abundance. We did not quantify plankton abundance in the present experiment. However, zooplankton data collected the previous year (1999) in our lakes showed no significant differences in daphnid abundance among the lakes $\left(F_{3,48}=0.47, P>0.65\right)$ and showed that daphnid abundance in pelagic habitats is $\sim 11$ times greater on average than in littoral habitats $\left(F_{2,48}=9.3, P<0.0005\right.$; Table 1$)$. In addition, similar patterns of plankton abundance between and within these lakes have been demonstrated in 1994 (Landry 1997, Landry et al. 1999). Finally, greater plankton abundance in pelagic waters is a general feature of lake ecosystems (Wetzel 1983).

These lakes were also chosen because bird predation on age- 0 trout is low, and especially for the fact that the common loon (Gavia immer), a potentially significant predator on age- 0 trout, was unable to access these small lakes and was never observed there for over eight years prior to and including our experiment. In 1999, we quantified bird predation on age- 0 trout stocked into these lakes at a density of 15000 trout/ha that contained adult trout, and found that birds killed only a small proportion. Loons were an important factor to control for because loons swallow prey underwater, making it impossible to know how many age- 0 trout they might consume. We surveyed for the presence of potential piscivorous birds from dawn to dusk, every second day, from the time of stocking until the fall population assessments. In addition, detailed focal animal observations of bird predators were performed from dawn to dusk to determine species-specific ingestion rates of age0 trout. Average ingestion rates were then combined with the frequency of occurrence of each piscivorous bird species for each lake over the season to estimate total number of age- 0 trout killed (Table 1). The most common and important piscivores were Great Blue Heron (Ardea herodias) and Belted Kingfisher (Ceryle alcyon). The estimated total number of age- 0 trout killed by bird predators in these lakes in 1999 is presented in Table 1; these values represent $1-2.5 \%$ of the initial age0 trout population (C. Beckmann, unpublished data). Predation by wading and perching bird predators, such as herons and kingfishers, is therefore unlikely to have been a significant source of age- 0 trout mortality during the present experiment.

\section{Estimation of mortality and growth}

We estimated fall population size by intensive gillnet sampling during the first 2.5 wk of October. Gillnet densities were standardized among lakes based on lake area and ranged from 400 to $500 \mathrm{~m}^{2} \cdot$ ha $\cdot$ night, following the identical netting effort and protocol used by Post et al. (1999) in these same lakes. We set sinking and floating experimental gillnets with graded, stretched mesh ranging in size from 13 to $89 \mathrm{~mm}$ for five nights in all habitats. Nets were set during the day and retrieved $\sim 24 \mathrm{~h}$ later. All captured fish not already dead were euthanized. In order to assess the relative proportion of the age- 0 trout cohort inhabiting pelagic vs. littoral habitats, we also set a standardized effort of fine-mesh floating gillnet for one net-night in the pelagic zone, because our standard netting protocol uses fine-mesh gillnets that sample to a maximum depth of $2.5 \mathrm{~m}$. Fork length (FL) of captured fish was measured to the nearest $1 \mathrm{~mm}$, and a subsample of not less than 500 individuals was weighed to the nearest $0.1 \mathrm{~g}$.

The summed catch over five nights of netting was adjusted to account for the size-dependent probability of capturing fish in gillnets. To do this, we estimated a mean capture probability model that expresses the proportion of fish of a particular size captured over the five nights of netting. This model was estimated from mark and recapture data collected in 1993 and 1994 in these same lakes. A total of 7503 fish ranging in size from 50 to $328 \mathrm{~mm}$ were captured, marked, and released just prior to fall netting in lakes with age- 0 trout densities that varied from 500 to 12000 trout/ha. The proportion of marked fish in each $5-\mathrm{mm}$ size interval recaptured over the five nights of netting follows a binomial probability distribution into which we could substitute various models to predict the probability of capture. The most likely model describing the data was determined by maximum likelihood and comparison of AICc statistics for each (Burnham and Anderson 1998). The most parsimonious model was a four-parameter logistic function as follows:

$$
P_{\text {capture }}=0.431\left(\frac{1}{\left[1+e^{-(-136+1.18 \mathrm{FL})}\right]^{0.02}}\right)
$$

where $P_{\text {capture }}$ is the proportion of fish of a given FL interval captured over five consecutive nights of gillnetting. This algorithm describes a steeply increasing function between 50 and $125 \mathrm{~mm}$ FL and a constant capture probability for fish $>125 \mathrm{~mm}$ (A. J. Paul, unpublished data). Because the mean capture probability was estimated using data from lakes with predators that largely restrict age- 0 trout distribution to the littoral zone, we further adjusted our estimate of the total number of survivors by the proportion of individuals estimated to inhabit the pelagic zone vs. the littoral zone (i.e., habitats $<2.5 \mathrm{~m}$ deep, see Results). We used mean fall mass as a surrogate for seasonal growth rate. Mean fall mass was calculated by dividing the sample of 
weighed fish into $10-\mathrm{mm}$ size bins, calculating a mean mass for each, then multiplying by the estimated number of survivors in each size bin (after adjusting the catch for the mean capture probability in each size interval).

\section{Spatial behavior of age-O and adult trout}

Three different gillnet types $(1.5 \mathrm{~m}, 2.5 \mathrm{~m}$, and $5 \mathrm{~m}$ deep) were used to sample shallow littoral, deep littoral, and pelagic habitats, respectively. Each net consisted of graded mesh sizes in the following order: 13-, 16-, 20-, and 25-mm stretched mesh. We likely underestimated absolute numbers of fish in any given habitat, because age0 trout $<45 \mathrm{~mm}$ FL are not vulnerable to the nets during the summer. This bias will therefore underestimate age0 trout size distributions in lakes with lower growth. However, this netting bias does not affect our fall estimates of growth and survival, because we captured no age-0 trout $<50 \mathrm{~mm}$ FL. Despite the small mesh sizes in these nets, we captured many adult trout, which provided information on their relative spatial distribution as well. Nets were set on bottom, parallel to the shoreline along the 1.5- and 2.5-m depth contours using the 1.5-m and 2.5-m nets, respectively. The 5-m deep net was set as a floating net in the pelagic zone in areas not less than $6 \mathrm{~m}$ deep. Nets were set midday, for $1 \mathrm{~h}$ in August and $0.5 \mathrm{~h}$ in early September. Captured fish were removed, and nets were re-set for the next "net trial." The modal number of net trials was eight (range $=6-8$ ). Two measures of spatial distribution were used: (1) probability of capture, defined as the proportion of net sets that caught at least one fish, and (2) relative habitat use, defined as the catch-per-unit-effort (number of fish per square meter of net per hour) in a particular habitat multiplied by the volume of that particular habitat divided by the total volume-corrected catch on that lake-day (see Landry et al. 1999). This second measure provides an estimate of the proportion of the age- 0 trout cohort that inhabit different habitats within a given lake. This measure was used to describe the spatial behavior of the adult trout that were captured in the same nets.

\section{Statistical analysis}

Working at the scale of whole-systems necessitates loss of statistical power associated with few replicates and the potential for an inflated type II error rate. Consequently, we used maximum likelihood techniques to find the most likely model given the data rather than relax the traditional (and arbitrary) level of significance of $\alpha=0.05$ (Hilborn and Mangel 1997, Burnham and Anderson 1998). Significance of treatment effects was determined by a likelihood-ratio test that is asymptotically $\chi^{2}$ distributed (Hilborn and Mangel 1997). Therefore, a $\chi^{2}$ result with $P<0.05$ is interpreted as being significantly more likely than a null model, where the effect is constant. Age-0 trout mortality and mean fall mass was analyzed assuming normally distributed er- rors on data that were arcsine square-root transformed and $\log _{e}$ transformed, respectively. Analysis by maximum likelihood was done in PROC GENMOD (SAS version 8.0; SAS Institute 1998). In addition, we also provide parametric $R^{2}$ values to express effect sizes for the most likely model. The probability of capturing age-0 trout in the pelagic habitat was analyzed using PROC GENMOD by assuming binomial distributed errors for the raw data. We similarly analyzed the proportion of the age- 0 trout cohort caught in each habitat using GENMOD, but assumed normal errors on data that were arcsine square-root transformed. Finally, we assessed the cost of predator presence to age- 0 trout in terms of foregone growth by comparing observed changes in mean mass over successive sampling periods to a predicted maximum mean mass. We used the growth equation of Iwama and Tautz (1981) developed from hatchery-raised rainbow trout fed to satiation. Changes in mean mass over each period were expressed as a percentage of the predicted maximum mass increase over that period given observed mean water temperatures in the littoral zone. Differences between treatments in the percentage of maximum mean mass achieved were determined by likelihood ratio tests, and $95 \%$ confidence intervals for each treatment mean were determined from likelihood profiles. If the confidence interval included the predicted maximum growth (i.e., $100 \%$ ), we considered it not statistically different. This was done since a one-sample $t$ test on so few replicates has very low power. Body size variation of age- 0 trout between habitats within lakes was analyzed using individuals as replicates.

\section{RESULTS \\ Evidence for flexible habitat use}

Age-0 trout were observed in both littoral and pelagic habitats of predator-free lakes, but their distribution was restricted to the less profitable littoral zone (Table 1) in lakes where adult trout were present (Fig. 1). No age- 0 trout were captured in the pelagic habitat in August or in September in lakes with trout predators (Fig. 1). By contrast, 53\% and 69\% of pelagic net-sets captured at least one age- 0 trout in lakes without trout predators in August $\left(\chi^{2}=16, P<0.0001\right)$ and September $\left(\chi^{2}=21, P<0.0001\right)$, respectively. A greater proportion of the age- 0 trout cohort used shallow habitats than deep littoral and pelagic habitats in August and in September $\left(\chi^{2}=45, P<0.0001\right.$ and $\chi^{2}=8.3$, $P<0.02$, respectively; Fig. 1). However, age-0 trout used shallow habitats less and deep littoral and pelagic habitats more in the absence of adult trout predators, resulting in the significant interaction between predator presence and habitat in August and September $\left(\chi^{2}=\right.$ $16, P<0.001$ and $\chi^{2}=7.5, P<0.025$, respectively; Fig. 1). Age-0 trout did not distribute themselves according to the distribution of food abundance (towards the pelagic habitat) when in the absence of adult trout 

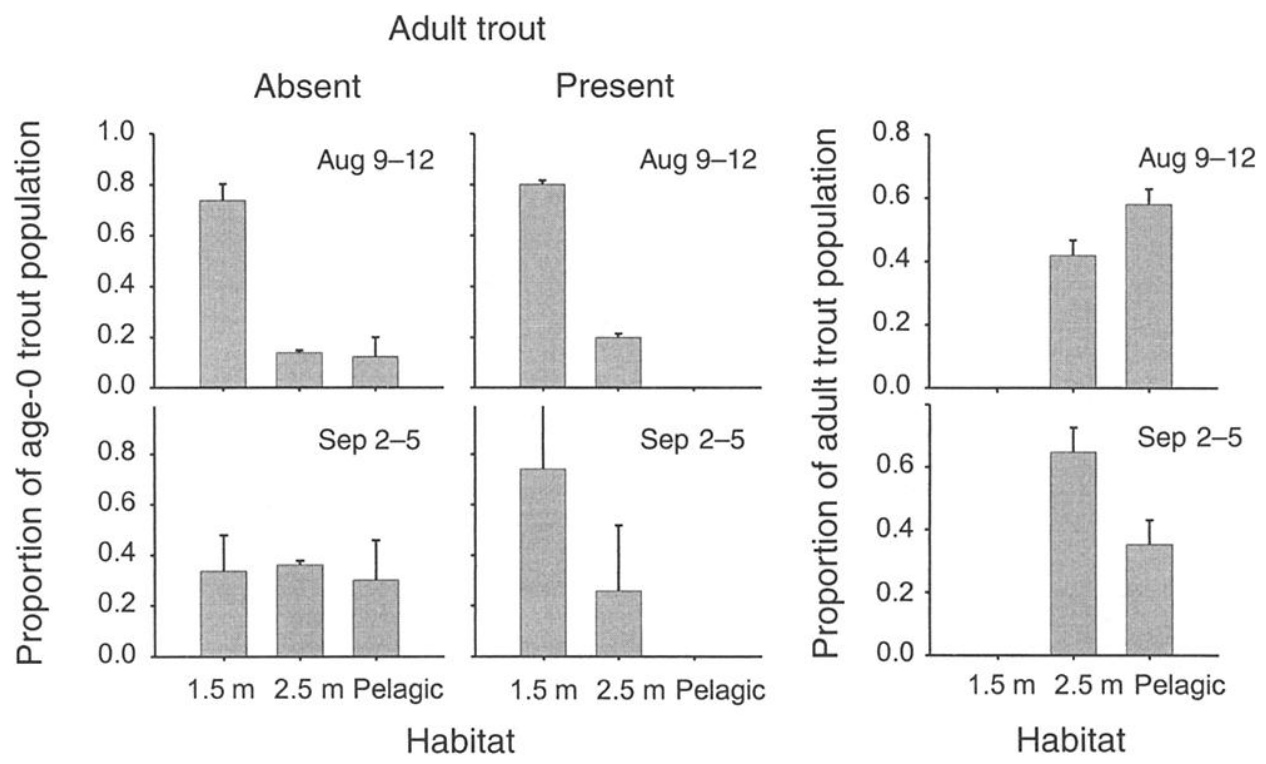

Fig. 1. Proportion of the age-0 trout (Oncorhynchus mykiss) cohorts captured in each of three habitats in relation to the presence or absence of trout predators and sampling date, and the proportion of adult rainbow trout cohorts captured in each of three habitats in the study lakes. Each bar represents the mean + 1 SE of two populations (lakes).

predators in August as predicted, but they did have a more even distribution among habitats in September (Fig. 1). In contrast, the entire age-0 trout cohort inhabited the littoral zone in lakes that possessed adult trout predators (Fig. 1).

The distribution of age- 0 trout was in the opposite direction to the distribution of adult trout predators that, when present, were captured in deep littoral and pelagic habitats exclusively (Fig. 1). In fact, not a single adult trout was captured in the shallow littoral habitat in any of the net trials during August or September (Fig. 1).

There was no evidence to support the alternate hypothesis that differential use of pelagic habitats by age0 trout between predator treatments was due to a sizedependent (ontogenetic) habitat shift associated with higher growth rates in lakes without adult trout. In August, age- 0 trout in littoral habitats in lakes with trout predators were just as large as age- 0 in pelagic habitats in lakes without trout predators (Fig. 2). There also was no evidence of size-dependent use of deep littoral or pelagic habitats in the absence of predators, but some evidence for it in the presence of predators (Fig. 2). The fork length of age-0 trout did not differ among habitats within predator-free lakes during $\mathrm{Au}$ gust or September (BP3: August, $F_{2,305}=1.0, P>0.3$ and September, $F_{2,182}=2.4, P>0.08$; SMOKE: August, $F_{2,327}=1.5, P>0.2$ and September, $F_{2,27}=1.7$, $P>0.1)$. Size of age-0 trout did not differ among habitats in BP1 (August, $F_{1,148}=0.4, P>0.5$ and September, not applicable), but larger individuals were captured in deeper habitats in September in BP2 (August, $F_{1,74}=3.9, P>0.05$ and September, $F_{1,20}=11.8$, $P<0.005)$.
By early October, patterns of habitat use by age- 0 trout among predation treatments were unchanged, but with one exception: There was evidence of size-related use of pelagic habitats in one of the lakes with trout predators (Fig. 3). Overnight gillnetting revealed that the proportion of age- 0 trout in pelagic vs. littoral habitats was significantly greater in populations without adult trout than in populations with adults $\left(\chi^{2}=12.2\right.$, $P<0.0005)$. On average, $44 \%$ of age- 0 trout inhabited the pelagic zone in populations without adult trout $(\mathrm{BP} 3=51 \%$, SMOKE $=37 \%)$ in comparison to $2 \%$ in populations with adults present $(\mathrm{BP} 1=0 \%, \mathrm{BP} 2=$ $4 \%$ ). Low use of the pelagic habitat by young trout in the presence of adult trout in BP2 was the result of a small number of captures $(n=8)$ that was linked to greater growth in BP2 as compared to BP1, where none were captured in the pelagic habitat (Fig. 3). Young trout reached a maximum fork length of only $82 \mathrm{~mm}$ in BP1, and none were captured in the pelagic zone. By contrast, fish reached $108 \mathrm{~mm}$ in BP2, and the smallest individual captured in the pelagic habitat was 84 mm (Fig. 3). Age-0 trout captured in the pelagic habitat in BP2 were significantly larger than those in the littoral zone (mean difference $=14 \mathrm{~mm}$ longer, separate variances $\left.t_{8}=7.3, P<0.001\right)$. In contrast, there were no biologically significant differences in body size of age0 trout between littoral and pelagic habitats in populations without trout predators (Fig. 3). Mean fork lengths of age- 0 trout were no different between littoral and pelagic habitats in BP3 (mean difference $=0.5$ $\mathrm{mm}$, separate variances $t_{580}=0.88, P>0.3$ ), but were slightly smaller in SMOKE (mean difference $=2 \mathrm{~mm}$, separate variances $\left.t_{505}=7.3, P<0.001\right)$. 


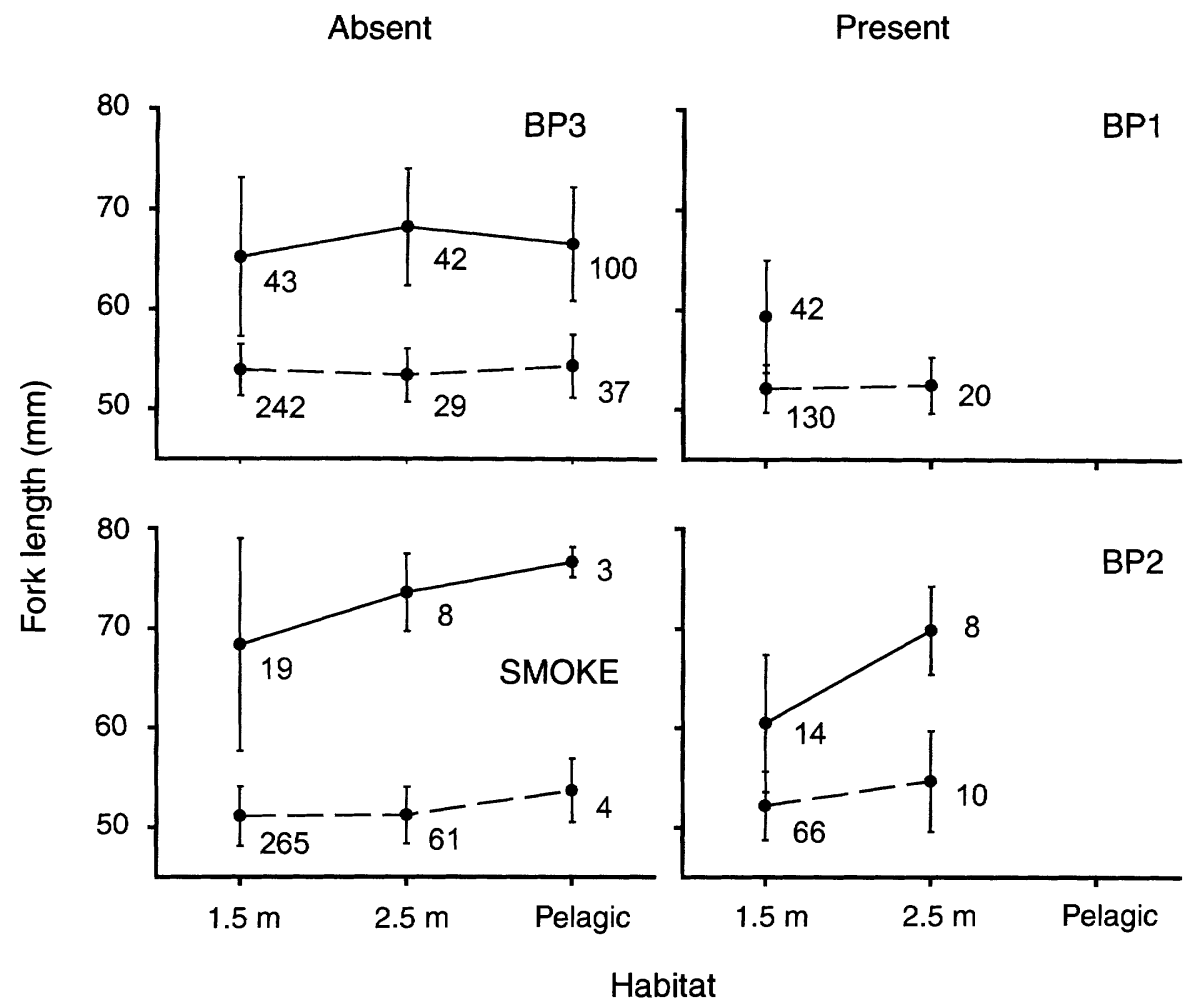

FIG. 2. Mean fork length of age- 0 trout (mean $\pm 1 \mathrm{SE}$ ) in each lake in relation to sampling date (dashed series = August; solid series = September), habitat, and predation treatment. The total sample size of trout captured in each habitat is given beside each mean fork length.

\section{Population-level consequences of flexible habitat use}

Exclusive use of the less productive littoral habitat by age- 0 trout in lakes with adult trout led to reduced growth and survival over the growing season (Fig. 4). Age- 0 trout experienced high mortality when in the presence of adult trout despite the fact that they resided primarily in the shallowest habitats where adults were never captured (Fig. 4A). In fact, $95 \%$ of the variation in age- 0 trout mortality could be explained by the presence or absence of adult trout $\left(F_{1,3}=38.3, P<0.03\right)$. That statistical model predicts that mortality in the absence of adult trout is $36 \%(95 \% \mathrm{CI}=20-53 \%)$ in comparison to $90 \%$ in the presence of adults $(95 \%$ CI $=81-96 \%)$. These mortality values translate to instantaneous mortality rates of $2.8 \%$ and $0.5 \%$ per day for populations with and without adult trout, respectively.

In the presence of adult trout, mean fall mass of age0 trout (a surrogate for growth rate) was reduced by almost one-half (Fig. 4B). Eighty-three percent of the variation in mean autumn mass of age- 0 trout could be explained by the presence or absence of adult trout, but this result was not significant at the $\alpha=0.05$ level $\left(F_{1,3}=10.0, P>0.05\right)$. However, this statistical model was significantly more likely than a null model de- scribing constant mass of age- 0 trout in October $\left(\chi^{2}=\right.$ 7.2, $P<0.01$ ), and predicts a mean autumn mass of $7.3 \mathrm{~g}$ in the absence of adult trout $(95 \% \mathrm{CI}=5.1-10.3$ g) compared to only $4.0 \mathrm{~g}$ in the presence of adult trout $(95 \% \mathrm{CI}=3.1-5.0 \mathrm{~g})$.

The growth cost incurred by age- 0 trout in the presence of adult trout predators increased steadily over time (Fig. 5). Age-0 trout grew at maximum rates in all populations over the early summer period (Fig. 5), and the proportion of maximum mean mass achieved did not differ between predator treatments $\left(\chi^{2}=2.9\right.$, $P>0.09$ ). Later, age-0 trout grew below maximum rates over the late summer period in lakes with adult trout, whereas growth was still maximal in populations without adult trout (Fig. 5). Age-0 trout achieved only $66 \%$ of maximal growth in lakes with predators during this period in contrast to $89 \%$ in lakes without predators $\left(\chi^{2}=5.6, P<0.02\right)$. During early autumn, young trout grew below maximum rates in all lakes (Fig. 5), although young trout growth was nearer the maximum in lakes without adult trout than in lakes with adults $\left(\chi^{2}=6.7, P<0.01\right)$.

\section{Discussion}

Our manipulations of predators revealed that (1) young trout have flexible and adaptive habitat use at 
Trout predators

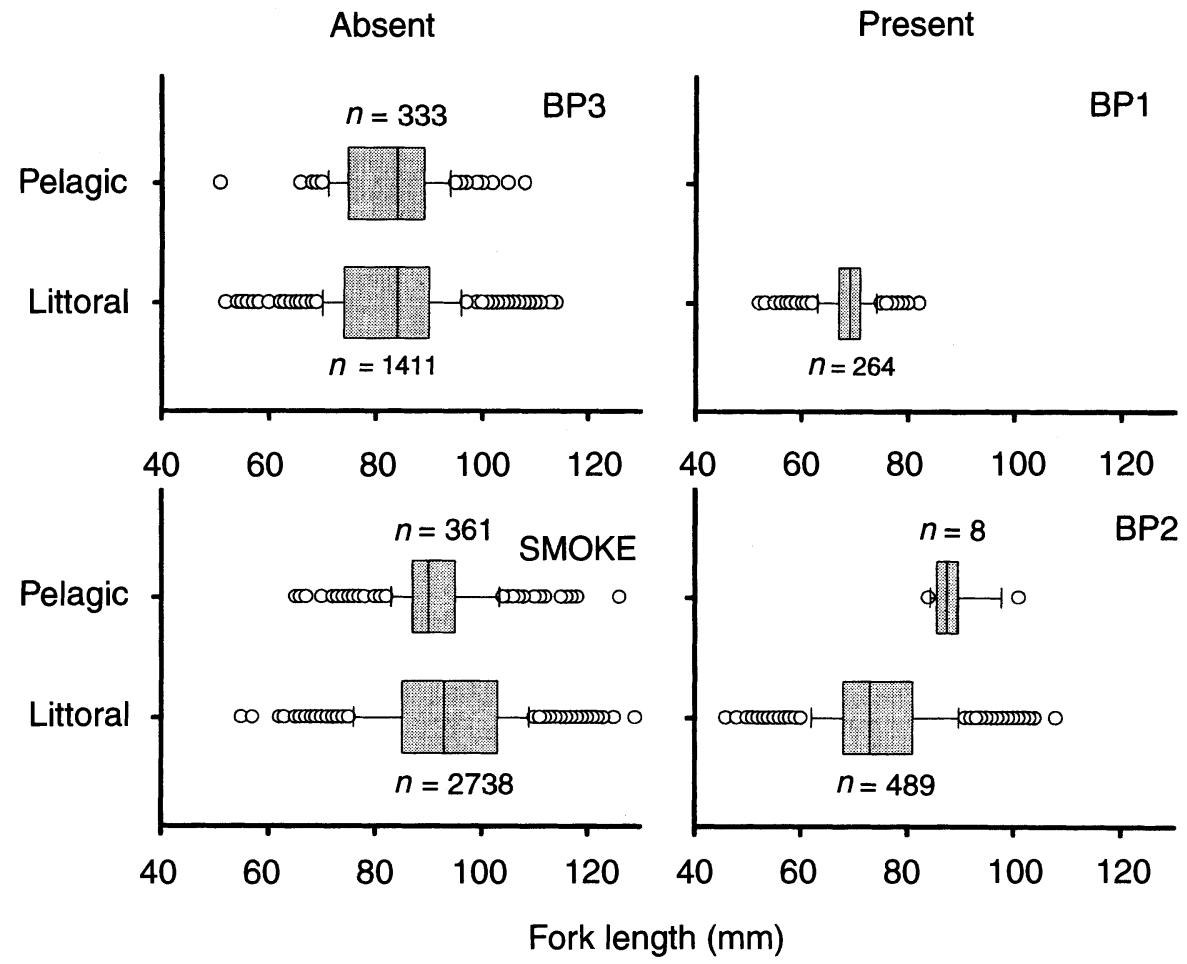

FIG. 3. Age-0 trout fork length in October for each lake in relation to the habitat they were captured in and predation treatment. Boxes encompass $50 \%$ of the values, vertical lines inside boxes designate the means, regions within whiskers represent $90 \%$ of values, and symbols (open circles) represent individual data points.

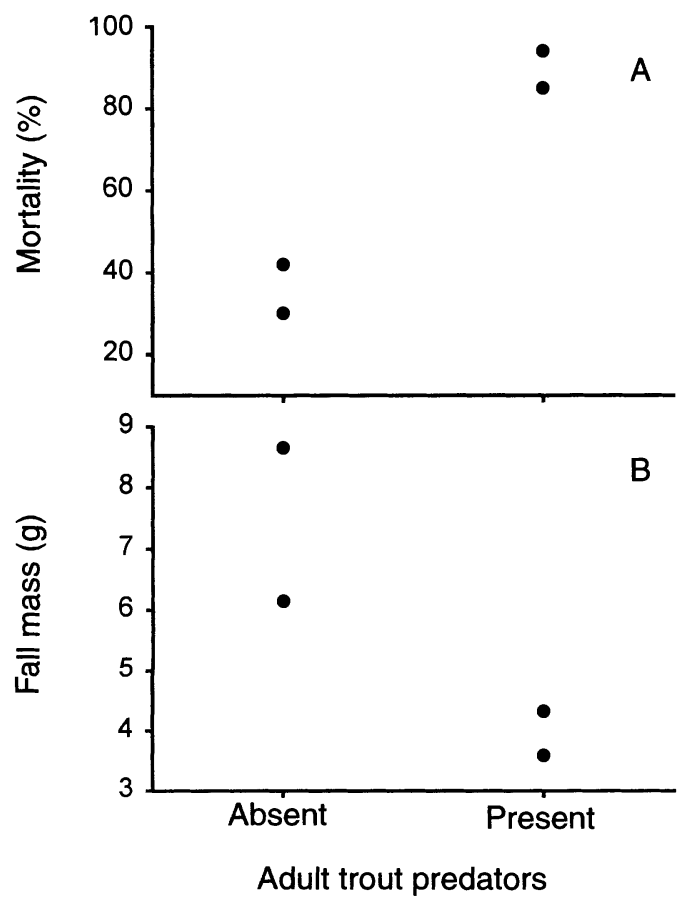

FIG. 4. (A) Mortality and (B) mean autumn mass estimates for each age- 0 trout population in relation to the presence or absence of adult trout predators in the study lakes. the whole-system scale, and (2) cohorts experienced large differences in growth and mortality during their first growing season as a result of differences in habitat use. Age- 0 trout used all habitats in the absence of adult trout predators, but restricted their habitat use to the less profitable, but safer, littoral zone when adult trout were present. Thus, use of nearshore habitats by age- 0 trout in lakes represents a facultative behavior whereby individuals assess variation in food availability (Table 1) and predation risk (Fig. 1), and apparently trade-off benefits of rapid growth with risk of predation mortality. Consequently, mean autumn mass of age-0 trout cohorts was almost two times greater when predators were absent. Nonetheless, age- 0 trout experienced high mortality in the presence of adult trout, but had they occupied the pelagic habitat, predator encounter rates and predation mortality would have been higher. In fact, there were six times as many survivors when adult trout were absent (autumn population densities of 9600 and 1500 trout/ha in predatorfree and predator lakes, respectively). Our study provides a valuable large-scale test of the classic study by Werner et al. (1983) showing flexible habitat use by young centrarchid fish in response to predation risk; their study was conducted in a single small pond and was unreplicated. Our findings are also consistent with 


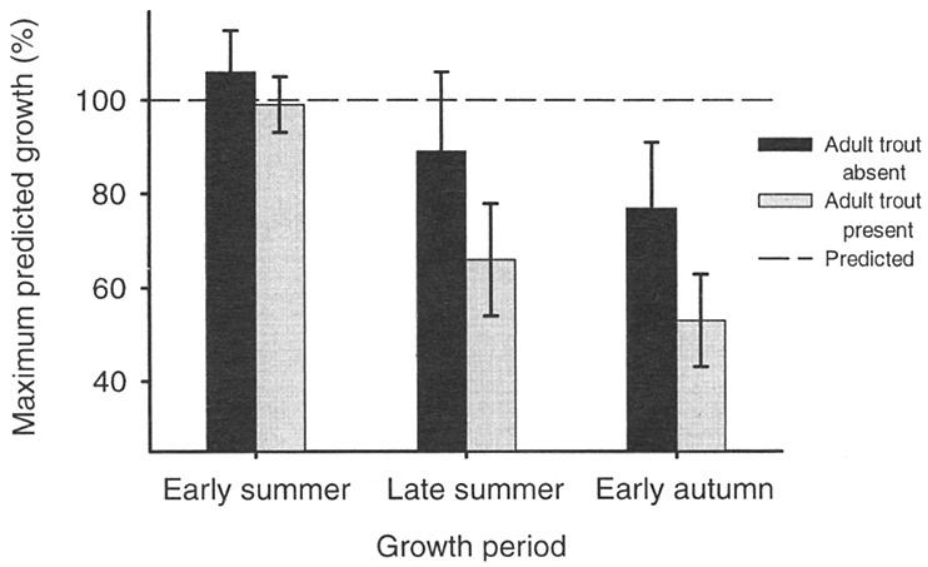

FIG. 5. Growth of age- 0 trout expressed as a percentage of the predicted maximum (from Iwama and Tautz 1981; see Methods) during three successive time intervals through the growing season. Each bar represents the mean $\pm 95 \% \mathrm{CI}$ of two lakes. those obtained from other smaller scale experiments (see Diehl and Eklöv 1995, and Lima 1998b).

Early in the experiment, age- 0 trout did not distribute themselves according to the distribution of food resources (Table 1) in lakes without trout predators. By September, young trout used the pelagic habitat considerably more. The low use of the pelagic habitat early in the season stands in contrast to findings from smaller scale experiments in which fish rapidly used the open and more profitable habitat (Diehl and Eklöv 1995, Lima 1998b), perhaps because confined fish more rapidly assess risk and/or experience food resource limitation. For instance, in an 11-d pond experiment, Tabor and Wurtsbaugh (1991) found that $78 \%$ of age- 0 rainbow trout occupied "offshore" areas when trout predators were absent. The "underuse" of pelagic habitats in our study was evident almost one month after stocking, and given the low mortality in these predator-free lakes, densities of age- 0 trout in the littoral habitats were likely greater than in lakes with trout predators. However, initial underuse of the pelagic habitat in the absence of predators may be explained by conservative, or relatively fixed, antipredator behavior. Initially conservative, or fixed, antipredator behavior is expected to evolve if gathering information about the predation environment increases vulnerability (Sih 1987). Since mortality of age- 0 trout is strongly size dependent in our lakes when in the presence of adult trout (Landry 1997, see also Johnsson 1993), we might also expect the cost of gathering information is high. Eklöv and Persson (1996) provide an example of a fixed antipredator behavior in young fish and suggest that it is adaptive given that adult fish predators are always present in natural populations. However, given that age- 0 trout were growing at maximum rates in all populations during the early summer, there was little reason for them to leave the littoral zone at that time. Later, growth was less than maximum in all populations, and there was a corresponding increase in the use of the pelagic habitat in lakes without predators. However, this would not explain the use of pelagic habitats by age- 0 trout when they were growing at maximum rates in the absence of predators. The relatively few individuals in the pelagic habitat may therefore represent those that have assessed absence of risk.

We found evidence suggesting that age- 0 trout are sensitive to size-dependent risk of predation. In the presence of adult trout, larger age- 0 trout were more likely to inhabit the deep littoral habitat than the shallow littoral habitat. At the end of the growing season, a small percentage of age- 0 trout in one of the lakes with adult trout occupied the pelagic zone. Young trout in this lake were larger than individuals in the other lake containing adult trout. Indeed, the likelihood of age- 0 trout being captured and eaten by adult trout is strongly size dependent, whereby smaller (Johnsson 1993, Landry 1997) and slower growing (Post et al. 1999) individuals experience greater mortality. Our estimate of the growth effect due to the presence of adult trout is likely conservative, with mean mass estimates biased upwards as a result of smaller individuals being removed from the population at high rates.

Age- 0 trout experienced high mortality from adult trout despite the shift in habitat use towards shallow littoral areas with low food abundance (Table 1), but few or no predators (Fig. 1). We could not confine age0 trout to the pelagic region to quantify mortality associated with that habitat, but we can infer mortality must be higher in the pelagic habitat given higher encounter rates with adult trout (Fig. 1). Antipredator behavior (habitat shifts) often reduces, but does not prevent, mortality in fish predator-prey systems (e.g., Tonn et al. 1992, Diehl and Eklöv 1995 and citations therein, Persson et al. 1996, 1999, Post et al. 1999) and other predator-prey systems (Lima 1998b). Tabor and Wurtsbaugh (1991) found that $96 \%$ of age- 0 rainbow trout were located inshore when in the presence of trout predators, but still experienced six times greater mortality and $24 \%$ lower growth than young trout in enclosures lacking predators. We speculate that high mortality of age- 0 trout in lakes with adult trout is the result of increased foraging effort (risk-taking) by individuals 
that are constrained by a short growing season in which to accumulate sufficient lipid reserves to survive winter (e.g., Werner and Anholt 1993, McNamara and Houston 1994). We are currently exploring these hypotheses in an effort to gain a mechanistic understanding of the large variation in young prey fish mortality seen in our lakes (Post et al. 1999).

Our experiment does not allow us to precisely quantify mortality from cannibalism. Yet, differences in mortality between treatments must have been proportional to the magnitude of cannibalism. Furthermore, the direction of habitat shift by prey fish indicates the relative risks of fish vs. avian predation in aquatic systems (Crowder et al. 1997). Prey fish move to shallow water and/or complex habitats offering refuge in response to piscivorous fish, but, when the dominant predators are wading or perching birds, the shift is towards deeper water (Crowder et al. 1997 and references therein). Estimates of bird predation during the previous year indicate that bird predators are unlikely to account for much of the between-lake or betweentreatment differences in age- 0 trout mortality given that $<3 \%$ of age- 0 trout were eaten by birds, even when young trout were largely confined to shallow areas in the presence of adult trout.

Reduced growth is a common indirect (nonlethal) consequence of predation risk in aquatic and terrestrial systems (Sih 1987, Lima and Dill 1990, Diehl and Eklöv 1995, Lima 1998b). Differential mortality could result in a "thinning effect" that yields negligable growth differences among cohorts (e.g., Walters and Juanes 1993, Van Buskirk and Yurewicz 1998). It is notable, therefore, that between-treatment differences in both growth and mortality were large by the end of the growing season. Reduced growth of age- 0 trout in the presence of adult trout could result not just from lower daphnid abundance in shallow habitats, but also from reduction of lake-wide daphnid abundance by adult trout (Post et al. 1999). Nonetheless, observed differences in the mean mass of age- 0 trout at the end of the growing season appeared to result from increasing food limitation over the season that was greater in lakes with adult trout than in lakes without them (Fig 5 ). The growth differences may have even longer term consequences for survival if the probability of overwinter starvation mortality is size dependent (Post and Evans 1989, Post and Parkinson 2001) and given that growth and survival of the cohort the following season is size and density dependent (Post et al.1999).

Our results show that rapid and flexible habitat shifts previously observed for prey at smaller spatial and temporal scales also occur at the whole-system scale, but with one caveat: Antipredator behavior may be constrained for early developmental stages. In addition, habitat shifts by prey have population-level consequences in terms of growth and survival that develop and persist over long time scales. Demonstration of large-scale and long-term consequences of flexible hab- itat use stresses the importance of behavior in predatorprey interactions.

\section{ACKNOWLEDGMENTS}

Thanks to Cam Mackenzie, Mark Hebblewhite, and Christa Beckmann for their field assistance. This research was supported by NSERC strategic and operating grants to J. R. Post and by the government of British Columbia to E. A. Parkinson. P. A. Biro was supported by an NSERC Postgraduate Scholarship. Thanks to the staff at the Fraser Valley Fish Hatchery for their help with fall netting and stocking. We also thank Lennart Persson and two anonymous reviewers for their helpful comments on an earlier draft of this manuscript.

\section{Literature Cited}

Abramsky, Z., E. Strauss, A. Subach, B. P. Kotler, and A. Riechman. 1996. The effect of barn owls (Tyla albas on the activity and microhabitat selection of Gerbillus allenbyi and G. pyramidum. Oecologia 105:313-319.

Burnham, K. P., and D. R. Anderson. 1998. Model selection and inference: a practical information-theoretic approach. Springer-Verlag, New York, New York, USA.

Carpenter, S. R. 1996. Microcosm experiments have limited relevance for community and ecosystem ecology. Ecology 77:677-680.

Crowder, L. B., D. B. Squires, and J. A. Rice. 1997. Nonadditive effects of terrestrial and aquatic predators on juvenile estuarine fish. Ecology 78:1796-1804.

Diehl, S., and P. Eklöv. 1995. Effects of piscivore-mediated habitat use on resources, diet, and growth of perch. Ecology 76: $1712-1726$.

Eklöv, P., and L. Persson. 1996. The response of prey to the risk of predation: proximate cues for refuging juvenile fish. Animal Behaviour 51:105-115.

Fryxell, J. M., and P. Lundberg. 1997. Individual behavior and community dynamics. Chapman and Hall, New York, New York, USA.

Hilborn, R., and M. Mangel. 1997. The ecological detective: confronting models with data. Princeton University Press, Princeton, New Jersey, USA.

Irving, P. W., and A. E. Magurran. 1997. Context-dependent fright reactions in captive European minnows: the importance of naturalness in laboratory experiments. Animal Behaviour 53:1193-1201.

Iwama, G. K., and A. F. Tautz. 1981. A simple growth model for salmonids in hatcheries. Canadian Journal of Fisheries and Aquatic Sciences 38:649-656.

Johnsson, J. 1993. Big and brave: size selection affects foraging under risk of predation in juvenile rainbow trout, Oncorhynchus mykiss. Animal Behaviour 45:1219-1225.

Karels, T. J., A. E. Byrom, R. Boonstra, and C. J. Krebs. 2000. The interactive effects of food and predators on reproduction and overwinter survival of arctic ground squirrels. Journal of Animal Ecology 69:235-247.

Landry, F. 1997. Direct and indirect effects of interference competition in size-structured rainbow trout (Oncorhynchus mykiss) populations. Thesis. University of Calgary, Calgary, Alberta, Canada.

Landry, F., J. R. Post, and E. A. Parkinson. 1999. Spatial ontogeny of lentic age-0 rainbow trout, Oncorhynchus mykiss: whole lake manipulations of population size structure. Canadian Journal of Fisheries and Aquatic Sciences 56: 1916-1928.

Lima, S. L: 1998a. Non-lethal effects in the ecology of predator-prey interactions. BioScience 48:25-34.

Lima, S. L. 1998b. Stress and decision-making under the risk of predation: recent developments from behavioral, reproductive, and ecological perspectives. Advances in the Study of Behavior 27:215-290. 
$\rightarrow$ Lima, S. L., and P. A. Bednekoff. 1999. Temporal variatior $\rightarrow$ in danger drives antipredator behavior: the predation risk allocation hypothesis. American Naturalist 153:649-659.

Lima, S. L., and L. M. Dill. 1990. Behavioural decision: $\rightarrow$ made under the risk of predation: a review and prospectus. Canadian Journal of Zoology 68:619-640.

Lima, S. L., and P. A. Zollner. 1996. Towards a behavioral ecology of ecological landscapes. Trends in Ecology and Evolution 11:131-135.

Luttbeg, B., and O. J. Schmitz. 2000. Predator and prey models with flexible individual behavior and imperfect information. American Naturalist 155:669-683.

$\rightarrow$ McNamara, J. M., and A. I. Houston. 1994. The effect of a change in foraging options on intake rate and predation rate. American Naturalist 144:978-1000.

$\rightarrow$ Persson, L., J. Andersson, E. Wahlstrom, and P. Eklöv. 1996. Size-specific interactions in lake systems: predator gape limitation and prey growth rate and mortality. Ecology 77 900-911.

Persson, L., P. Bystrom, E. Wahlstrom, J. Andersson, and J. Hjelm. 1999. Interactions among size-structured populations in a whole-lake experiment: size- and scale-dependent processes. Oikos 87:139-156.

Post, J. R., and D. O. Evans. 1989. Size-dependent overwinter mortality of young-of-the-year yellow perch (Perca flavescens): laboratory, in situ enclosure and field experiments. Canadian Journal of Fisheries and Aquatic Sciences 46:1958-1968.

Post, J. R., and E. A. Parkinson. 2001. Energy allocation strategy in young fish: allometry and survival. Ecology $\mathbf{8 2}$. 1040-1051.

Post, J. R., E. A. Parkinson, and N. T. Johnston. 1998. Spatial and temporal variation in risk to piscivory of age- 0 rainbow trout: patterns and population consequences. Transaction: of the American Fisheries Society 127:932-942.

$\rightarrow$ Post, J. R., E. A. Parkinson, and N. T. Johnston. 1999. Density-dependent processes in structured fish populations: assessment of interaction strengths in whole-lake experiments. Ecological Monographs 69:155-175.

SAS Institute. 1998. SAS/STAT user's guide, version 8.0. Volume 1. SAS Institute, Cary, North Carolina, USA.
Schindler, D. W. 1990. Experimental pertubations of whole lakes as tests of hypotheses concerning ecosystem structure and function. Oikos 57:25-41.

Schmitz, O. J. 2001. From interesting details to dynamical relevance: toward more effective use of empirical insights in theory construction. Oikos 94:39-50.

Sih, A. 1987. Prey refuges and predator-prey stability. Theoretical Population Biology 31:1-12.

Sih, A., G. Englund, and D. Wooster. 1998. Emergent impacts of multiple predators on prey. Trends in Ecology and Evolution 13:350-355.

Sutherland, W. J. 1996. From individual behaviour to population ecology. Oxford University Press, Oxford, UK.

Tabor, R. A., and W. A. Wurtsbaugh. 1991. Predation risk and the importance of cover for juvenile rainbow trout in lentic systems. Transactions of the American Fisheries Society 120:728-738.

Tonn, W. M., C. A. Paszkowski, and I. J. Holopainen. 1992. Piscivory and recruitment: mechanisms structuring prey populations in small lakes. Ecology 73:951-958.

Van Buskirk, J., and K. L. Yurewicz. 1998. Effects of predators on prey growth rate: relative contributions of thinning and reduced activity. Oikos 82:20-28.

Walters, C. J., and F. Juanes. 1993. Recruitment limitation as a consequence of natural selection for use of restricted feeding habitats and predation risk taking by juvenile fishes. Canadian Journal of Fisheries and Aquatic Sciences 50: 2058-2070.

Werner, E. E., and B. R. Anholt. 1993. Ecological consequences of the trade-off between growth and mortality rates mediated by foraging activity. American Naturalist 142: 242-272.

$\rightarrow$ Werner, E. E., J. F. Gilliam, D. J. Hall, and G. G. Mittelbach. 1983. An experimental test of the effects of predation risk on habitat use in fish. Ecology 64:1540-1548.

Wetzel, W. 1983. Limnology. Saunders, New York, New York, USA.

$\rightarrow$ Wolff, M. S., and R. Davis-Born. 1997. Response of graytailed voles to odours of a mustelid predator: a field test. Oikos 79:543-548. 